\title{
Epigenetic impact of the parents' physical activity on the health of their children
}

\author{
Agnieszka Boroń \\ Department of Clinical and Molecular Biochemistry, \\ Pomeranian Medical University, Szczecin, Poland
}

\section{abstract}

All parents' dream is to have healthy children. The question whether the parents' lifestyle affects the quality of their progeny's health has been bothering scientists and society for many years. Based on epidemiological studies, it has been shown that physical activity during pregnancy is beneficial both for the health of the mother and the newborn. A significant number of studies conducted so far have shown that exercises performed by fathers modulate future generations by affecting the sperm epigenome. Epigenetics plays a key role in transmitting the response of the parents' environment and their lifestyle onto the characteristics and health of their progeny.

Key words: epigenetic, methylation, DNA, physical activity, children, parent.

\section{article details}

Article statistics: Word count: 2,753; Tables: 0; Figures: 0; References: 76

Received: September 2021; Accepted: September 2021; Published: September 2021

Full-text PDF: http://www.balticsportscience.com

Copyright @ Gdansk University of Physical Education and Sport, Poland

Indexation: Celdes, Clarivate Analytics Emerging Sources Citation Index (ESCl), CNKI Scholar (China National Knowledge Infrastructure), CNPIEC, DOAJ, EBSCO - Central \& Eastern European Academic Source, EBSCO - SPORTDiscus, EBSCO Discovery Service, Google Scholar, Index Copernicus, J-Gate, Naviga (Softweco, Primo Central (ExLibris), ProQuest - Family Health, ProQuest - Health \& Medical Complete, ProQuest - Illustrata: Health Sciences, ProQuest Nursing \& Allied Health Source, Summon (Serials Solutions/ProQuest, TDOne (TDNet), Ulrich's Periodicals Directory/ ulrichsweb, WorldCat (OCLC)

Funding: This research received no specific grant from any funding agency in the public, commercial, or not-for-profit sectors. Author has declared that no competing interest exists. Agnieszka Boroń, Department of Clinical and Molecular Biochemistry, Pomeranian Medical University, Szczecin, Poland, Ul. Powstańców WIkp.72, 70-111 Szczecin; e-mail: binia@pum.edu.pl; Tel. +48914661503

Open Access License: This is an open access article distributed under the terms of the Creative Commons Attribution-Non-Commercial-NoDerivatives 4.0 International (https://creativecommons.org/licenses/by-nc-nd/4.0/), which permits use, distribution, and reproduction in any medium, provided the original work is properly cited, the use is non-commercial and is otherwise in compliance with the license. 


\section{INTRODUCTION}

All parents' dream is to have healthy children. The question whether the parents' lifestyle affects the quality of their progeny's health has been bothering scientists and society for many years. Many years of research have shown that environmental factors in critical stages of development - such as the prenatal and perinatal period - may influence the risk of chronic diseases in the progeny [1, 2].

It is indisputable that physical exercise is an essential part of a healthy lifestyle. Exercise is recognized as an important non-pharmacological preventive and/or therapeutic intervention which may slow the progression or harmful effects of numerous metabolic, cardiovascular, oncological and neurodegenerative diseases [3].

Pregnant women are recommended physical activity and exercise by The American College of Obstetricians and Gynecologists (ACOG). According to the ACOG, in the absence of obstetric or medical complications or contraindications, physical activity during pregnancy is safe and desirable, and pregnant women should be encouraged to do or keep doing it [4]. Data from human and animal studies have demonstrated numerous benefits of physical exercise performed by pregnant women and fathers before their child is conceived. It has been revealed that regular aerobic exercise of mothers during pregnancy improves or maintains their physical fitness and may prevent excessive weight gain [5-7]. Observational studies of women exercising during pregnancy showed, among others, such positive effects as the reduction of the risk of gestational diabetes, gestational hypertension and Caesarean delivery [8-12]. Exercise during pregnancy may also lower glucose levels in women with gestational diabetes or help prevent pre-eclampsia [13, 14]. A systematic review and meta-analysis from 2017 found that in overweight and obese women in single pregnancies, compared with women leading a more sedentary life, aerobic exercise of around 30-60 minutes, 3-7 times a week, was associated with a reduction in the frequency of preterm births [15]. A 2019 systematic review and meta-analysis, however, demonstrated that in mothers with antenatal diseases (chronic hypertension, type 1 diabetes, and type 2 diabetes), prenatal exercises reduced the chances of a Caesarean section by $55 \%$ and did not increase the risk of complications for both the mother and the newborn [16].

The studies also showed that physical activity may be an important factor in the prevention of depressive disorders in women during the puerperium $[17,18]$. Proper exercise is good for both the mind and the body - skeletal muscles in particular. Exercise increases the efficiency of muscle metabolism, improves the biological functions of mitochondria, regulates the transformation of types of muscle fibers and increases muscle strength. Studies in recent years show that epigenetic regulation plays a very important role in all these processes. Epigenetics also means that the beneficial effects of physical exercise are inherited and passed on to future generations. Moreover, more and more evidence shows the protective effect of the parents' training on their progeny and its association with the prevention of chronic diseases, including obesity, diabetes and hypertension [19]. The mothers' or fathers' exercise - before their child is conceived - appears to be one of the most logical and cost-effective ways to potentially improve their progeny's health.

\section{EPIGENETICS}

Currently, epigenetics is defined as 'heritable changes in gene expression that occur without alteration in a DNA sequence'. We know three separate and intertwined mechanisms regulating the 'epigenome' - i.e. DNA methylation, histone modifications and non-coding RNA (ncRNA), particularly miRNA [20]. These processes affect transcript stability, DNA folding, nucleosome positioning, chromatin condensation and, ultimately, how the nucleus is arranged. They synergistically and collectively determine whether a gene is silenced 
or activated, and when and in what tissue it will be expressed. DNA changes mediated by any of these mechanisms are heritable - not only are they passed on to daughter cells, but also to subsequent generations [21].

DNA methylation refers to the covalent addition of a methyl group derived from S-Adenosyl-L-methionine to the fifth carbon of the cytosine ring resulting in the fifth base - 5-methylcytosine $(5 \mathrm{meC})$. The reaction is catalyzed by DNA methyltransferases and accessory proteins (Dnmt1, Dnmt3a, Dnmt3b, Dnmt2 and Dnmt3L). Primarily, in all eukaryotic species, methylation occurs in cytosines located 5' to guanines which are known as $\mathrm{CpG}$ dinucleotides (CpG) [22]. CpG dinucleotides in the genome are frequently found in dense clusters to form the so-called CpG islands. CpG islands mainly co-localize with promoters and transcription start sites. Unlike the vast majority of CpGs located in the intergenic regions and repetitive elements, $\mathrm{CpG}$ islands are typically unmethylated - regardless of the transcriptional activity of a neighboring gene - but if they become hypermethylated, they promote gene silencing [23]. While CpG methylation at transcription start sites is generally associated with gene silencing, recent studies have shown that DNA methylation - if it is in the gene body - may be positively correlated with gene transcription and have its impact on the occurrence of alternative splicing [24]. The results of the whole methylome DNA study revealed that abnormal methylation patterns in diseases are often absent in CpG islands, but occur in distal regulatory regions-such as enhancers and isolators - and in the so-called 'edge' regions that flank on both sides of the CpG island (up to $2 \mathrm{~kb}$ in distance) $[25,26]$. DNA methylation alters the binding of transcriptional factors and other proteins which interact with chromatin, and, as a result, fine-tune gene expression.

Non-coding RNAs (ncRNAs) that are not translated into proteins may be divided into two groups - i.e. ordinal non-coding RNA and regulatory non-coding RNA. Regulatory RNA is mainly categorized by size - short-chain non-coding RNAs (including siRNA, miRNA, and piRNA) and long non-coding RNA (lncRNA) [27, 28]. In recent years, many studies have shown that ncRNA plays an important role in epigenetic modification and may regulate expression at the gene and chromosome levels [29-31]. Many miRNAs are involved in the transmission of acquired traits to the progeny and have important biological functions, including cell proliferation, apoptosis, metabolism, neuronal patterns, hematopoietic differentiation, and the process of immunization. Furthermore, miRNAs may act as epigenetic modulators by targeting key enzymes responsible for epigenetic reactions, such as DNA methyltransferases (DNTM), histone deacetylases (HDAC) and methyltransferases (EZH) [32].

Histone modifications may also lead to the activation or suppression of gene expression. Linear DNA is wrapped in an octameric complex of two molecules of each of the four histone proteins - including H2A, H2B, H3, and H4-which form an array of nucleosomes. $\mathrm{N}$-terminal ends of histones contain a variety of post-translational modifications, including acetylation and methylation of lysine residues at $\mathrm{N}$-terminal ends of histones ( $\mathrm{H} 3$ and $\mathrm{H} 4$ ) which are the most correlated with transcriptional activity. Histone acetylation is usually associated with transcriptional activation as a result of lower affinity of an acetylated histone with DNA, which allows chromatin relaxation. Conversely, deacetylation of histones correlates with transcriptional silencing and the heterochromatic state [21]. Not only does histone acetylation facilitate destabilization of DNA-nucleosome interactions for active transcription, but-when provoked on a global scale-it promotes rearrangements in the three-dimensional genome architecture, thus enabling extensive translocation of genomic loci and regulatory regions to a nuclear pore complex [23, 33].

Some epigenetic modifications directly affect the cognitive functions of the body and are associated with better results in learning tests and a better memory [34] - for example with 
the very phenomenon of histone acetylation that is directly related to active transcription and the establishment of a long-term memory [35]. Histone levels are regulated by a balance between the protein content in histone acetyltransferase (HAT) and histone deacetylase (HDAC). HAT catalyzes the transfer of acetyl groups to histone proteins, whereas HDAC removes acetyl groups. It has been shown that overexpression of HDAC2 in the hippocampus impairs memory and long-term enhancement, whereas HDAC2 knockout mice show an improvement in memory [36]. HDAC2 is an important enzyme related to the process of learning and memorization, and its hyperactivity determines memory formation and synaptic plasticity [37, 38].

\section{MOTHER S PHYSICAL ACTIVITY}

Based on epidemiological studies, it has been shown that physical activity during pregnancy is beneficial both for the health of the mother and the newborn [39-43]. However, the impact of maternal exercise on fetal development - skeletal muscle development in particular - is largely unexplored and remains an interesting issue that requires a more in-depth analysis.

Skeletal muscles serve very important functions in the human body. They make it possible to move and be physically active, maintain a proper body posture, protect the skeleton and internal organs, regulate energy metabolism of the whole body and maintain immune homeostasis. Skeletal muscles make up around $40 \%$ of the body weight and are key to the proper use of glucose and lipids in the human body. Exercise protects against mitochondrial malfunction and muscle atrophy from diet-induced obesity, increases the basal metabolic rate, and prevents metabolic syndromes. The skeletal muscle epigenetic landscape modulated by physical exercise fine-tunes the delicate balance between gene expression and gene silencing controlled by transient or stable transcriptional or posttranscriptional mechanisms [44, 45].

It has been proven that skeletal muscle is a programmable tissue and can "remember" mechanical and metabolic stimuli in the early stages of life through epigenetic mechanisms, which affects its function throughout lifetime $[46,47]$. Epigenetic memory effects have recently been illustrated for key genes involved in mitochondrial biogenesis, including the most comprehensive transcription coactivator controlling energy metabolism - i.e. peroxisome proliferator-activated receptor gamma coactivator 1- $\alpha$ (PPARGC1A; PGC-1 $\alpha$ protein) [48].

Studies on mice have shown that maternal exercise activates AMPK and $\alpha$-KG mediated DNA demethylation - which is correlated with an increased oxidative capacity and exercise endurance-in the PPARGC1A gene promoter that permanently increases PPARGC1A expression in the progeny's muscles [49]. AMPK-AMP-activated protein kinase is the main regulator of energy metabolism [50]. It may be phosphorylated as a result of regular exercise, thereby triggering expression and phosphorylation of PGC-1 $\alpha$ [51, 52]. By increasing the concentration of $\alpha$-ketoglutarate $(\alpha-K G)$, AMPK is also an important mediator in epigenetic modifications, including DNA demethylation [53].

Laker et al. proved that maternal exercise during pregnancy may completely alleviate the progeny's metabolic disturbances caused by adverse effects of the mother's high-fat diet. In their studies they found that the mother's high-fat diet caused hypermethylation (eliminated by maternal exercise) of the PPARGC1A promoter at CpG-260 [54].

Apelin is a peptide and endogenous ligand of a $\mathrm{G}$ protein-coupled receptor that is mainly expressed in the placenta, adipose tissue and skeletal muscles in response to exercise [55]. Apelin increases the AMPK activity, which enhances mitochondrial biogenesis and the mitochondrial respiratory function, possibly by stimulating PGC-1 $\alpha$ expression [56]. It has 
been proven that maternal exercise increases the level of apelin in the fetus's circulation and adipose tissue of both the mother and her progeny [57]. Consequently, an increase in apelin in the muscles of the fetus and progeny was also found, which correlated with the AMPK activation and increased DNA demethylation in the PPARGC1A promoter.

Muscle fibers are divided into glycolytic and oxidative fibers, with oxidative fibers particularly rich in mitochondria and highly efficient in utilizing glucose and fatty acids [58]. It has been found that maternal exercise enhances the oxidative capacity of the progeny's muscles by changing the types of muscle fibers from glycolytic to oxidative without altering muscle mass, which may be associated with increased mitochondrial biogenesis [59].

A proper balance between DNA hypermethylation and demethylation in the hippocampus is essential for the proper function of neurons on which the memory processing is based. DNA hypermethylation is usually associated with silencing of genes which are important for cellular homeostasis. In contrast, DNA demethylation is associated with an increase in the expression of genes promoting plasticity, which, in turn, induces neuronal plasticity [60].

Several studies have demonstrated the benefits of maternal aerobic exercise for tasks related to memorization and learning performed by the progeny which are partially related to the high levels of the Brain Derived Neurotrophic Factor (BDNF) and hippocampal neurogenesis [61-63].

Segabinazi et al. [64] revealed that the progeny of mothers who had taken exercise before they became pregnant showed a decrease in global hippocampal DNA methylation in their adult life, which was related to cell proliferation in the hippocampus.

Dayi et al. [61] found that male adults whose mothers had exercised on a treadmill during pregnancy had a better learning curve. The progeny of mothers who exercised during pregnancy showed a decrease in the amount of HDAC2 in the hippocampus.

Meireles et al. [38] also proved that the progeny of mothers who had practiced strength training during pregnancy showed slightly better results in terms of memorization and learning tasks as well as a decrease in the HDAC2 level in the hippocampus. The progeny of mothers who exercised prior to gestation showed high cell proliferation and high IGF1 expression in the dentate gyrus of the hippocampus, as well as changes in global DNA methylation and $\mathrm{H} 4$ acetylation.

\section{FATHER S PHYSICAL ACTIVITY}

It is not only mothers' exercise that has its influence of the health of their children. A significant number of studies conducted so far have shown that exercises performed by fathers modulate future generations by affecting the sperm epigenome [65]. Spermatogenesis is an ongoing process and the father's life experiences may reprogram his sperm quality and epigenetic profile. Evidence suggests that physical exercises performed by fathers alter DNA methylation in their sperm [66].

Claycombe-Larson et al. [67] showed that paternal exercise reduces expression of IL-1 $\beta$ and TNF- $\alpha$ mRNA in the placenta, which results in a beneficial effect on its inflammation, fetal tissue weight and, consequently, on the progeny's body weight.

Several studies have revealed that aerobic exercise performed by fathers has a positive effect on the plasticity of neurons in their progeny, which significantly affects learning and memorization. Yin et al. [68] showed that paternal treadmill exercises improved spatial 
learning and memorization in their progeny-which was accompanied by increased expression of the brain derived neurotrophic factor (BDNF) and reelins in the hippocampus - compared to the progeny of fathers living a sedentary lifestyle. These two proteins play a significant role in neuronal survival, maturation and growth, and act as modulators for neurotransmitters.

Park et al. [69] also showed that paternal exercise improves spatial learning, increases expression of BDNF and the receptor tyrosine kinase B (TrkB) in the progeny.

Several independent research teams, including Mega et al. [70] and Spindler et al. [71], proved that aerobic exercise causes a significant reduction in global DNA methylation of the hippocampus in the progeny of fathers who take exercise, compared to the progeny of fathers living a sedentary lifestyle. The aerobic exercise protocol also induced changes in the expression of hippocampal genes related to the cell cycle and mitochondrial processes, as well as increased mitochondrial citrate synthase activity in the hippocampus. McGreevy et al. [72] suggest that mitochondrial integrity is crucial for cell differentiation and dendritogenesis in the neurons of the newborn children and that it may modify the progeny's capacity for memorization.

Batista et al. [73] discovered that paternal swimming training could improve the metabolic profile of the progeny's liver, thereby alleviating the harmful effects of obesity. Swimming training regulated lipogenesis of the CPT1, PPAR-1A and PRKAA2 genes and induced an increase in the PRKAA2 and pAMPK levels in the liver of the progeny exposed to a high-fat diet, compared to the control group. These changes were also accompanied by a decrease in the level of excessive fat build-up in the liver.

Krout et al. [74] showed that in the skeletal muscles of the progeny of fathers who do physical exercise, insulin signaling pathway genes (GLUT4, IRS1 and PI3K) are expressed more, which prevents the risk of type 2 diabetes.

However, McPherson et al. $[75,76]$ provided convincing evidence that swimming exercises performed by fathers who eat a high-fat diet lower the levels of free fatty acids, cholesterol and $\mathrm{C}$ - reactive protein in the blood of the progeny.

\section{CONCLUSIONS}

Recent studies have shown that parental physical activity plays a positive role in modulation of the progeny's phenotype. Not only is the progeny's health positively influenced by the mother's exercises done before and during pregnancy, but also by the father's exercise before their child is conceived. In addition, physical exercise done in the early stages of life appears to alleviate disadvantages inherited from the gestational environment and provides the progeny with long-term health benefits throughout their adult life. Adaptations related to physical activity are coordinated by epigenetic signaling which fine-tunes gene expression controlled by transient or stable transcriptional or post-transcriptional mechanisms. Undoubtedly, epigenetics plays a key role in transmitting the response of the parents' environment and their lifestyle onto the characteristics and health of their progeny. Therefore, it should be remembered that the varied patterns of DNA methylation in the skeletal muscle tissue of the progeny may, unfortunately, reflect "bad memories" resulting from the parents' lack of physical activity.

\section{REFERENCES}

[1] Falcão-Tebas F, Kuang J, Arceri C, Kerris JP, Andrikopoulos S, Marin EC, McConell GK. Four weeks of exercise early in life reprograms adult skeletal muscle insulin resistance caused by a paternal high-fat diet. J Physiol. 2019 Jan;597(1):121-136. https://doi.org/10.1113/JP276386 
[2] Falcão-Tebas F, Bento-Santos A, Fidalgo MA, et al. Maternal low-protein diet-induced delayed reflex ontogeny is attenuated by moderate physical training during gestation in rats. Br J Nutr. 2012 Feb;107(3):372-7. https://doi. org/10.1017/S0007114511002947

[3] Pedersen BK, Saltin B. Exercise as medicine - evidence for prescribing exercise as therapy in 26 different chronic diseases. Scand J Med Sci Sports. 2015 Dec;25 Suppl 3:1-72. https://doi.org/10.1111/sms.12581

[4] Physical Activity and Exercise During Pregnancy and the Postpartum Period: ACOG Committee Opinion, Number 804. Obstet Gynecol. 2020 Apr;135(4):e178-e188. https://doi.org/10.1097/AOG.0000000000003772

[5] de Oliveria Melo AS, Silva JL, Tavares JS, Barros VO, Leite DF, Amorim MM. Effect of a physical exercise program during pregnancy on uteroplacental and fetal blood flow and fetal growth: A randomized controlled trial. Obstet Gynecol. 2012;120:302-10. https://doi.org/10.1097/AOG.0b013e31825de592

[6] Price BB, Amini SB, Kappeler K. Exercise in pregnancy: effect on fitness and obstetric outcomes-a randomized trial. Med Sci Sports Exerc. 2012;44:2263-9. https://doi.org/10.1249/MSS.0b013e318267ad67

[7] Kramer MS, McDonald SW. Aerobic exercise for women during pregnancy. Cochrane Database System Rev. 2006 3:CD000180. https://doi.org/10.1002/14651858.CD000180.pub2

[8] Dye TD, Knox KL, Artal R, Aubry RH, Wojtowycz MA. Physical activity, obesity, and diabetes in pregnancy. Am J Epidemiol. 1997;146:961-5. https://doi.org/10.1093/oxfordjournals.aje.a009223

[9] Cordero Y, Mottola MF, Vargas J, Blanco M, Barakat R. Exercise is associated with a reduction in gestational diabetes mellitus. Med Sci Sports Exerc. 2015;47:1328-33. https://doi.org/10.1249/MSS.0000000000000547

[10] Dempsey JC, Sorensen TK, Williams MA, et al. Prospective study of gestational diabetes mellitus risk in relation to maternal recreational physical activity before and during pregnancy. Am J Epidemiol. 2004;159:663-70. https://doi. org/10.1093/aje/kwh091

[11] Liu J, Laditka JN, Mayer-Davis EJ, Pate RR. Does physical activity during pregnancy reduce the risk of gestational diabetes among previously inactive women? Birth. 2008;35:188-95. https://doi.org/10.1111/j.1523-536X.2008.00239.x

[12] Magro-Malosso ER, Saccone G, Di Tommaso M, Roman A, Berghella V. Exercise during pregnancy and risk of gestational hypertensive disorders: a systematic review and meta-analysis. Acta Obstet Gynecol Scand. 2017;96:921-31. https:// doi.org/10.1111/aogs.13151

[13] Jovanovic-Peterson L, Durak EP, Peterson CM. Randomized trial of diet versus diet plus cardiovascular conditioning on glucose levels in gestational diabetes. Am J Obstet Gynecol. 1989;161:415-9. https://doi.org/10.1016/0002 9378(89)90534-6

[14] Garcia-Patterson A, Martin E, Ubeda J, Maria MA, de Leiva A, Corcoy R. Evaluation of light exercise in the treatment of gestational diabetes. Diabetes Care. 2001;24:2006-7. https://doi.org/10.2337/diacare.24.11.2006

[15] Magro-Malosso ER, Saccone G, Di Mascio D, Berghella V. Exercise during pregnancy and risk of preterm birth in overweight and obese women: a systematic review and meta-analysis of randomized controlled trials. Acta Obstet Gynecol Scand. 2017;96:263-73. https://doi.org/10.1111/aogs.13087

[16] Adesegun D, Cai C, Sivak A, Chari R, Davenport MH. Prenatal exercise and pre-gestational diseases: a systematic review and meta-analysis. J Obstet Gynaecol Can. 2019;41:1134-43.e17. https://doi.org/10.1016/j.jogc.2018.10.007

[17] Kolomanska-Boguck D, Mazur-Bialy Al. Physical Activity and the Occurrence of Postnatal Depression. A Systematic Review. Medicine (Kaunas). 2019;55:560. https://doi.org/10.3390/medicina55090560

[18] Nakamura A, van der Waerden J, Melchior M, Bolze C, El-Khoury F, Pryor L. Physical activity during pregnancy and postpartum depression: systematic review and meta-analysis. J Affect Disord. 2019;246:29-41. https://doi. org/10.1016/j.jad.2018.12.009

[19] Harris JE, Baer LA, Stanford KI. Maternal exercise improves the metabolic health of adult offspring. Trends Endocrinol Metab. 2018 Mar;29(3):164-177. https://doi.org/10.1016/j.tem.2018.01.003

[20] Cheung P, Lau P. Epigenetic regulation by histone methylation and histone variants. Mol Endocrinol. 2005 Mar;19(3):563-73. https://doi.org/10.1210/me.2004-0496

[21] Tang WY, Ho SM. Epigenetic reprogramming and imprinting in origins of disease. Rev Endocr Metab Disord. 2007 Jun;8(2):173-82. https://doi.org/10.1007/s11154-007-9042-4

[22] Dolinoy DC, Das R, Weidman JR, Jirtle RL. Metastable epialleles, imprinting, and the fetal origins of adult diseases Pediatr Res. 2007;61:30R-7R. https://doi.org/10.1203/pdr.0b013e31804575f7

[23] Beiter T, Nieß AM, Moser D. Transcriptional memory in skeletal muscle. Don't forget (to) exercise. J Cell Physiol. 2020 Jul;235(7-8):5476-5489. https://doi.org/10.1002/jcp.29535

[24] Jones PA. Functions of DNA methylation: islands, start sites, gene bodies and beyond. Nat Rev Genet. 2012 May 29;13(7):484-92. https://doi.org/10.1038/nrg3230

[25] Edgar R, Tan PP, Portales-Casamar E, Pavlidis P. Meta-analysis of human methylomes reveals stably methylated sequences surrounding $\mathrm{CpG}$ islands associated with high gene expression. Epigenetics Chromatin. 2014 Oct 23;7(1):28. https://doi.org/10.1186/1756-8935-7-28

[26] Ziller MJ, Gu, H, Muller F, Donaghey J, Tsai LT, Kohlbacher O, Meissner A. Charting a dynamic DNA methylation landscape of the human genome. Nature. 2013;500(7463):477-481. https://doi.org/10.1038/nature12433

[27] Zaratiegui M, Irvine DV, Martienssen RA. Noncoding RNAs and gene silencing. Cell. 2007 Feb 23;128(4):763-76. https://doi.org/10.1016/j.cell.2007.02.016

[28] Ponting CP, Oliver PL, Reik W. Evolution and functions of long noncoding RNAs. Cell. 2009 Feb 20;136(4):629-41. https://doi.org/10.1016/j.cell.2009.02.006

[29] Guennewig B, Cooper AA. The central role of noncoding RNA in the brain. Int Rev Neurobiol. 2014;116:153-94. https://doi.org/10.1016/B978-0-12-801105-8.00007-2

[30] Ghildiyal M, Zamore PD. Small silencing RNAs: an expanding universe. Nat Rev Genet. 2009 Feb;10(2):94-108. https://doi.org/10.1038/nrg2504

[31] Wei JW, Huang K, Yang C, Kang CS. Non-coding RNAs as regulators in epigenetics (Review). Oncol Rep. 2017 Jan;37(1):3-9. https://doi.org/10.3892/or.2016.5236 
[32] Yao Q, Chen Y, Zhou X. The roles of microRNAs in epigenetic regulation. Curr Opin Chem Biol. 2019 Aug;51:11-17. https://doi.org/10.1016/j.cbpa.2019.01.024

[33] Brown CR, Kennedy CJ, Delmar VA, Forbes DJ, Silver P.A. Global histone acetylation induces functional genomic reorganization at mammalian nuclear pore complexes. Genes and Development; 2008;22(5): 627-639. https://doi. org/10.1101/gad.1632708

[34] Day JJ, Sweatt JD, Epigenetic mechanisms in cognition, Neuron. 2011;70:813-829. https://doi.org/10.1016/j. neuron.2011.05.019

[35] Peixoto L, Abel T. The role of histone acetylation in memory formation and cognitive impairments, Neuropsychopharmacology. 2013;38:62-76. https://doi.org/10.1038/npp.2012.86

[36] Guan JS, Haggarty SJ, Giacometti E, et al. HDAC2 negatively regulates memory formation and synaptic plasticity, Nature. 2009;459:55-60. https://doi.org/10.1038/nature07925

[37] Morris MJ, Mahgoub M, Na ES, Pranav H, Monteggia LM. Loss of histone deacetylase 2 improves working memory and accelerates extinction learning. J Neurosci. 2013;33:6401-6411. https://doi.org/10.1523/JNEUROSCI.1001-12.2013

[38] Meireles ALF, Segabinazi E, Spindler C, et al. Maternal resistance exercise promotes changes in neuroplastic and epigenetic marks of offspring's hippocampus during adult life. Physiol Behav. 2021 Mar 1;230:113306. https://doi. org/10.1016/j.physbeh.2020.113306

[39] Barakat R, Perales M, Garatachea N, Ruiz JR, Lucia A. Exercise during pregnancy. A narrative review asking: what do we know? Br J Sports Med. 2015;49:1377-1381. https://doi.org/10.1136/bjsports-2015-094756

[40] Davenport MH, Meah VL, Ruchat SM, et al. Impact of prenatal exercise on neonatal and childhood outcomes: A systematic review and meta-analysis. Br J Sports Med. 2018;52:1386-1396. https://doi.org/10.1136/ bjsports-2018-099836

[41] Gustafsson MK, Stafne SN, Romundstad PR, Mørkved S, Salvesen K, Helvik AS. The effects of an exercise programme during pregnancy on health-related quality of life in pregnant women: A Norwegian randomised controlled trial. BJOG. 2016;123:1152-1160. https://doi.org/10.1111/1471-0528.13570

[42] Nascimento SL, Surita FG, Cecatti JG. Physical exercise Turing pregnancy: A systematic review. Curr Opin Obstet Gynecol. 2012;24:387-394. https://doi.org/10.1097/GCO.0b013e328359f131

[43] Son JS, Chae SA, Wang H, et al. Maternal inactivity programs skeletal muscle dysfunction in offspring mice by attenuating apelin signaling and mitochondrial biogenesis. Cell Rep. 2020 Dec 1;33(9):108461. https://doi. org/10.1016/j.celrep.2020.108461

[44] Barrès R, Zierath JR. The role of diet and exercise in the transgenerational epigenetic landscape of T2DM. Nat Rev Endocrinol. 2016;12(8):441-451. https://doi.org/10.1038/nrendo.2016.87

[45] McGee SL, Walder KR. Exercise and the skeletal muscle epigenome. Cold Spring Harb Perspect Med. 2017;7(9):a029876. https://doi.org/10.1101/cshperspect.a029876

[46] Sharples AP, Stewart CE, Seaborne RA. Does skeletal muscle have an 'epi'-memory? The role of epigenetics in nutritional programming, metabolic disease, aging and exercise. Aging Cell. 2016;15(4):603-616. https://doi. org/10.1111/acel.12486

[47] Beleza J, Stevanović-Silva J, Coxito P, Costa RC, Ascensão A, Torrella JR, Magalhães J. Building-up fit muscles for the future: Transgenerational programming of skeletal muscle through physical exercise. Eur J Clin Invest. 2021 Feb 13:e13515. https://doi.org/10.1111/eci.13515

[48] Perry CG, Lally J, Holloway GP, Heigenhauser GJ, Bonen A, Spriet LL. Repeated transient mRNA bursts precede increases in transcriptional and mitochondrial proteins during training in human skeletal muscle. J Physiol. 2010 Dec 1;588(Pt 23):4795-810. https://doi.org/10.1113/jphysiol.2010.199448

[49] Son JS, Chae SA, Wang H, et al. Maternal Inactivity Programs Skeletal Muscle Dysfunction in Offspring Mice by Attenuating Apelin Signaling and Mitochondrial Biogenesis. Cell Rep. 2020 Dec 1;33(9):108461. https://doi. org/10.1016/j.celrep.2020.108461

[50] Habegger KM, Hoffman NJ, Ridenour CM, Brozinick JT, Elmendorf JS. AMPK enhances insulin-stimulated GLUT4 regulation via lowering membrane cholesterol. Endocrinology. 2012;153:2130-2141. https://doi.org/10.1210/en.20112099

[51] Canto' C, Jiang LQ, Deshmukh AS, et al. Interdependence of AMPK and SIRT1 for metabolic adaptation to fasting and exercise in skeletal muscle. Cell Metab. 2010;11:213-219. https://doi.org/10.1016/j.cmet.2010.02.006

[52] Menzies KJ, Singh K, Saleem A, Hood DA. Sirtuin 1-mediated effects of exercise and resveratrol on mitochondrial biogenesis. J Biol Chem. 2013;288:6968-6979. https://doi.org/10.1074/jbc.M112.431155

[53] Yang Q, Liang X, Sun X, et al. AMPK/ $\alpha-$ Ketoglutarate Axis Dynamically Mediates DNA Demethylation in the Prdm16 Promoter and Brown Adipogenesis. Cell Metab. 2016 Oct 11;24(4):542-554. https://doi.org/10.1016/j.cmet.2016.08.010

[54] Laker RC, Altıntaş A, Lillard TS, et al. Exercise during pregnancy mitigates negative effects of parental obesity on metabolic function in adult mouse offspring. J Appl Physiol (1985). 2021 Mar 1;130(3):605-616. https://doi.org/10.1152/ japplphysiol.00641.2020

[55] Son JS, Liu X, Tian Q, et al. Exercise prevents the adverse effects of maternal obesity on placental vascularization and fetal growth. J Physiol. 2019;597:3333-3347. https://doi.org/10.1113/JP277698

[56] Hesselink, M.K.C., Schrauwen-Hinderling, V., and Schrauwen, P. (2016). Skeletal muscle mitochondria as a target to prevent or treat type 2 diabetes mellitus. Nat. Rev. Endocrinol. 12, 633-645. https://doi.org/10.1038/nrendo.2016.104

[57] Son JS, Zhao L, Chen Y, et al. Maternal exercise via exerkine apelin enhances brown adipogenesis and prevents metabolic dysfunction in offspring mice. Sci. Adv. 2020;6:eaaz0359. https://doi.org/10.1126/sciadv.aaz0359

[58] Misu H, Takayama H, Saito Y, et al. Deficiency of the hepatokine selenoprotein P increases responsiveness to exercise in mice through upregulation of reactive oxygen species and AMP-activated protein kinase in muscle. Nat Med. 2017;23:508-516. https://doi.org/10.1038/nm.4295

[59] Chen X, Luo X, Chen D, Yu B, He J, Huang Z. Arginine promotes porcine type I muscle fibres formation through improvement of mitochondria biogenesis. Br J Nutr. 2020;123:499-507. https://doi.org/10.1017/S000711451900309X 
[60] Fernandes J, Arida RM, Gomez-Pinilla F. Physical exercise as an epigenetic modulator of brain plasticity and cognition. Neurosci Biobehav Rev. 2017;80:443-456. https://doi.org/10.1016/j.neubiorev.2017.06.012

[61] Dayi A, Agilkaya S. Ozbal S, et al. Maternal aerobic exercise during pregnancy can increase spatial learning by affecting leptin expression on offspring's early and late period in life depending on gender, Sci World J. 2012:Article ID 429803, https://doi.org/10.1100/2012/429803.

[62] Akhavan MM, Miladi-Gorji H, Emami-Abarghoie M, Safari M, Sadighi-Moghaddam B, Vafaei AA, Rashidy-Pour A. Maternal voluntary exercise Turing pregnancy enhances the spatial learning acquisition but not the retention of memory in rat pups via a TrkB-mediated mechanism: the role of hippocampal BDNF expression, Iran J Basic Med. Sci. 2013;16:955-961.

[63] Gomes Da Silva S, De Almeida AA, Fernandes J, et al. Maternal exercise Turing pregnancy increases BDNF levels and cell numbers in the hippocampal formation but not in the cerebral cortex of adult rat offspring, PLoS ONE. 2016; 11:1-15. https://doi.org/10.1371/journal.pone.0147200

[64] Segabinazi E, Spindler C, de Meireles ALF, et al. Effects of maternal physical exercise on global DNA methylation and hippocampal plasticity of rat male offspring. Neuroscience. 2019;418:218-230. https://doi.org/10.1016/j. neuroscience.2019.08.036

[65] Denham J, O'Brien BJ, Harvey JT, Charchar FJ. Genome-wide sperm DNA methylation changes after 3 months of exercise training in humans. Epigenomics. 2015 Aug;7(5):717-31. https://doi.org/10.2217/epi.15.29

[66] Vieira de Sousa Neto I, Fontes W, Prestes J, de Cassia Marqueti R. Impact of paternal exercise on physiological systems in the offspring. Acta Physiol (Oxf). 2021 Apr;231(4):e13620. https://doi.org/10.1111/apha.13620

[67] Claycombe-Larson KG, Bundy AN, Roemmich JN. Paternal high-fat diet and exercise regulate sperm miRNA and histone methylation to modify placental inflammation, nutrient transporter mRNA expression and fetal weight in a sex-dependent manner. J Nutr Biochem. 2020;81:108373. https://doi.org/10.1016/j.jnutbio.2020.108373

[68] Yin MM, Wang W, Sun J, et al. Paternal treadmill exercise enhances spatial learning and memory related to hippocampus among male offspring. Behav Brain Res. 2013;253:297-304. https://doi.org/10.1016/j.bbr.2013.07.040

[69] Park HS, Kim TW. Paternal physical exercise improves spatial learning ability by enhancing hippocampal neuroplasticity in male pups born from obese maternal rats. J Exerc Rehabil. 2017;13(3):266-272. https://doi.org/10.12965/ jer.1734998.499

[70] Mega F, de Meireles ALF, Piazza FV, et al. Paternal physical exercise demethylates the hippocampal DNA of male pups without modifying the cognitive and physical development. Behav Brain Res. 2018;348:1-8. https://doi.org/10.1016/j. bbr.2018.03.040

[71] Spindler C, Segabinazi E, Meireles ALF, et al. Paternal physical exercise modulates global DNA methylation status in the hippocampus of male rat offspring. Neural Regen Res. 2019;14(3):491-500. https://doi.org/10.4103/16735374.245473

[72] McGreevy KR, Tezanos P, Ferreiro-Villar I, et al. Intergenerational transmission of the positive effects of physical exercise on brain and cognition. Proc Natl Acad Sci USA. 2019;116(20):10103-10112. https://doi.org/10.1073/ pnas.1816781116

[73] Batista RO, Budu A, Alves-Silva T, et al. Paternal exercise protects against liver steatosis in the male offspring of mice submitted to high fat diet. Life Sci. 2020;263:118583. https://doi.org/10.1016/j.lfs.2020.118583

[74] Krout D, Roemmich JN, Bundy A, Garcia RA, Yan L, Claycombe-Larson KJ. Paternal exercise protects mouse offspring from high-fat-diet-induced type 2 diabetes risk by increasing skeletal muscle insulin signaling. J Nutr Biochem. 2018 Jul;57:35-44. https://doi.org/10.1016/j.jnutbio.2018.03.013

[75] McPherson NO, Lane M, Sandeman L, Owens JA, Fullston T. An Exercise-Only Intervention in Obese Fathers Restores Glucose and Insulin Regulation in Conjunction with the Rescue of Pancreatic Islet Cell Morphology and MicroRNA Expression in Male Offspring. Nutrients. 2017 Feb 9;9(2):122. https://doi.org/10.3390/nu9020122

[76] McPherson NO, Owens JA, Fullston T, Lane M. Preconception diet or exercise intervention in obese fathers normalizes sperm microRNA profile and metabolic syndrome in female offspring. Am J Physiol Endocrinol Metab. 2015 May 1;308(9):E805-21. https://doi.org/10.1152/ajpendo.00013.2015 